\title{
WPŁYW ZAJEĆC W SZKOLE RODZENIA NA ZMNIEJSZENIE LĘKU PORODOWEGO
}

\section{THE INFLUENCE OF ANTENATAL CLASSES ON REDUCING FEAR OF CHILDBIRTH}

\author{
Sławomir Szymański ${ }^{1}$, Wojciech Brączyk ${ }^{2}$, Violetta Konstanty-Kurkiewicz ${ }^{3}$ \\ ${ }^{1}$ Zakład Pielęgniarstwa Położniczo-Ginekologicznego \\ Pomorski Uniwersytet Medyczny w Szczecinie \\ ${ }^{2}$ Studia stacjonarne, fizjoterapia \\ Pomorski Uniwersytet Medyczny w Szczecinie \\ ${ }^{3}$ Klinika Położnictwa i Ginekologii \\ Pomorski Uniwersytet Medyczny w Szczecinie
}

DOI: https://doi.org/10.20883/pielpol.2017.29

\section{STRESZCZENIE}

Cel. Celem niniejszej pracy była analiza czynników wpływających na lęk porodowy oraz poznanie sposobów radzenia sobie z nim. Materiały i metody. Metodą badawczą był sondaż diagnostyczny przeprowadzony za pomocą kwestionariusza pytań. Materiał do badań stanowiły odpowiedzi 84 ciężarnych respondentek uczestniczących w zajęciach szkoły rodzenia na terenie Szczecina i okolic.

Wyniki. Większość badanych kobiet potwierdziła, że najbardziej boją się porodu. Obniżenie tego uczucia dzięki zajęciom w szkole rodzenia zgłosiło 66 z 84 pytanych. Badaniu ankietowemu poddano 84 kobiety w ciąży uczęszczające do Szkoły Rodzenia. Badane posiadały w większości wykształcenie wyższe. Czas trwania ciąży podczas uczestnictwa w zajęciach w Szkole Rodzenia wynosił 28,39 $\pm 4,37$ tygodnia.

Wnioski. Aktywne uczestnictwo w zajęciach szkoły rodzenia pozytywnie przekłada się na zmniejszenie lęku i stresu przedporodowego. Lęk przedporodowy zależny jest od wieku ciężarnej w większym stopniu niż od rodności.

SŁOWA KLUCZOWE: szkoła rodzenia, poród, lęk, ciąża.

\section{Wprowadzenie}

Instytucja szkoły rodzenia to nieodzowny składnik organizacji opieki nad kobietami będącymi w ciąży. Idea tego przedsięwzięcia, które miało przygotować ciężarne do porodu, pojawiła się w XIX w. na zachodzie Europy. Jednakże rozwój szkół przypada na wiek XX, kiedy to

\section{ABSTRACT}

Aim. The aim of this study was to analyze the factors that may affect the birth anxiety as well as knowledge how to deal with it. Material and methods. The research method was a diagnostic survey carried out by means of a questionnaire. Studied material consisted of answers included in the questionnaire which was flled in by 84 pregnant women participating in antenatal classes in Szczecin and in the surrounding areas.

Results. Most of the women $(78.57 \%$ of them ) said that they feared the most childbirth. The reduction of this feeling through the ante-natal classes was reported by 66 of the 84 respondents. Eighty-four pregnant women who attended antenatal classes on a regular basis were surveyed. Women participating in the study had, in most cases, higher education (58.33\%). The duration of pregnancy at the time of participation in the classes was 28.39 \pm 4.37 weeks

Conclusions. Active participation in antenatal classes positively reflected in reducing prenatal anxiety and stress. Prenatal fear depends on the age of the pregnant woman to a greater extent than on their parity.

KEYWORDS: antenatal classes, childbirth, anxiety, pregnancy.

angielski położnik G.D. Read wprowadził pojęcie „Koło Reada" [1].

Od tego czasu notuje się coraz większy rozwój ilości szkół rodzenia, ale także ciągłe podnoszenie kwalifikacji personelu tam zatrudnianego, z uwagi na duże oczekiwania rodziców u progu macierzyństwa. 


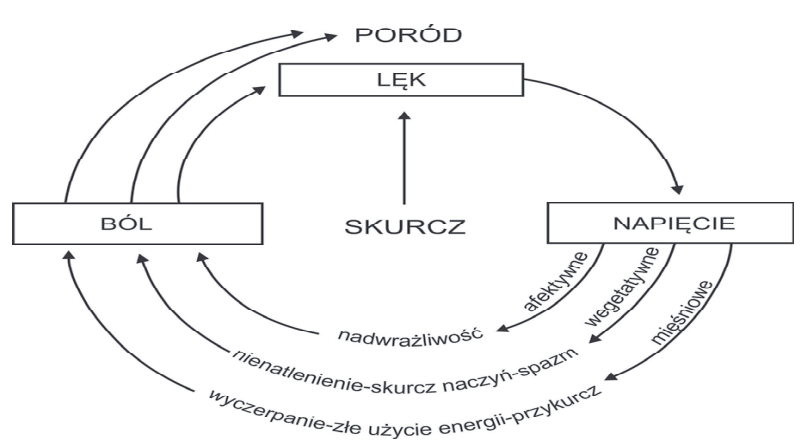

Poród/Delivery, Lęk/Fear, Ból/Pain, Napięcie: afektywne, wegetatywne, mięśniowe/Tension: affective, vegetative, muscular, Skurcz/Contraction, Nadwrażliwość/Hypersensitivity

Nienatlenienie - skurcz naczyń - spazm/Oxygen deficiency - vasospasm - spasm, Wyczerpanie - złe użycie energii - przykurcz/Exhaustion - improper energy use - contracture

Rycina 1. Koło Reada

Figure 1. Circle of Read

Źródło: Kwiatek M., Gęca T., Biegaj-Fic J.: Szkoła rodzenia - Profil pacjentek oraz wpływ zajęć na przebieg porodu oraz stan noworodka. Medycyna Ogólna i Nauki o Zdrowiu. 2011, 17, 111-115

\section{Cel pracy}

Celem niniejszej pracy była analiza czynników wpływających na lęk porodowy oraz poznanie sposobów radzenia sobie $z$ nim.

\section{Materiał i metody}

Materiałem do badań były odpowiedzi udzielone przez 84 ciężarne uczestniczące w zajęciach szkoły rodzenia na terenie Szczecina. Badanie przeprowadzono na podstawie formularza ankiety.

Do analizy statystycznej pozyskanych danych wykorzystano program Statistica v. 9.0 firmy StatSoft Polska. Mierzone parametry przedstawiono, podając dla zmiennych ciągłych średnie arytmetyczne, odchylenia standardowe, medianę, wartości minimalne i maksymalne oraz ilość przypadków, natomiast dla zmiennych dyskretnych ilość przypadków oraz wartość procentową. W analizie statystycznej wykorzystano test chi-kwadrat oraz test U Manna Whitneya.

\section{Wyniki}

Średni wiek ciężarnych wyniósł 28,8 \pm 5,69 lat. Najmłodsza ciężarna miała 17 lat, najstarsza 43 lata (Tabela 1). Ciężarne były w większości wieloródkami (średnia liczba przebytych porodów 1,9 $\pm 1,2)$. Średnia rodność badanej populacji wyniosła 1,17 $\pm 0,43$ porodów. Czas trwania ciąży podczas uczestnictwa w Szkole Rodzenia wynosił 28,39 $\pm 4,37$ tygodnia.
Tabela 1. Dane populacji badanej

Table 1. Data of studied population

\begin{tabular}{ccccc}
\hline & N & $\begin{array}{c}\text { Średnia } \pm \text { SD/ } \\
\text { Average } \pm \text { SD }\end{array}$ & $\begin{array}{c}\text { Minimum/ } \\
\text { Minimum }\end{array}$ & $\begin{array}{c}\text { Maximum/ } \\
\text { Maximum }\end{array}$ \\
\hline $\begin{array}{c}\text { wiek ciężarnej/ } \\
\text { age of participants } \\
\text { rodność/parity }\end{array}$ & 84 & $28,8 \pm 5,69$ & 17 & 43 \\
$\begin{array}{c}\text { czas trwania ciąży } \\
\text { [w tygodniach]/ } \\
\text { the duration of pregnancy } \\
\text { [in weeks] }\end{array}$ & 84 & $1,17 \pm 0,43$ & 1 & 3 \\
\hline
\end{tabular}

$\mathrm{N}$ - liczebność/ number

SD - odchylenie standardowe/ standard deviation

Źródło: opracowanie własne

Source: author's own analysis

Większość badanych kobiet posiadała wykształcenie wyższe - 58,33\%. Kobiety z wykształceniem średnim stanowiły $35,71 \%$ badanych, z kolei kobiety z wykształceniem podstawowym stanowiły $5,95 \%$ badanych.

Zdecydowana większość badanych kobiet potwierdziła, że pojawia się u nich lęk przed porodem - 78,57\%. Lęku nie odczuwało 21,43\% badanych kobiet.

Średnia rodność u osób zgłaszających lęk przed porodem wyniosła 1,14 $\pm 0,39$, podczas gdy u osób niezgłaszających 1,28 $\pm 0,57$ (Tabela 2). Różnice nie były istotne statystycznie $(p=0,266)$.

Tabela 2. Występowanie lęku przed porodem a liczba przebytych ciąż Table 2. Occurrence of fear of childbirth and the number of pregnancies undergone

\begin{tabular}{ccccc}
\hline & $\begin{array}{c}\text { Występowanie } \\
\text { lęku przed poro- } \\
\text { dem/Occurrence } \\
\text { of fear of childbirth }\end{array}$ & $\begin{array}{c}\text { Srednia/ } \\
\text { Average }\end{array}$ & SD & $\mathrm{p}^{*}$ \\
\hline $\begin{array}{c}\text { Liczba przebytych } \\
\text { ciąż/Number of } \\
\text { pregnancies }\end{array}$ & Tak/Yes & 1,14 & 0,39 & NS \\
\hline
\end{tabular}

* test chi-kwadrat/chi-square test

SD - odchylenie standardowe/standard deviation

Źródło: opracowanie własne

Source: author's own analysis

Kobiety, które odczuwały lęk przed porodem, na skutek uczestnictwa w zajęciach szkoły rodzenia i po przyjęciu przekazywanych tam informacji stwierdziły, że ów lęk się zmniejszył (Tabela 3). Wyniki nie były istotne statystycznie $(p=0,087)$. 
Tabela 3. Występowanie lęku przed porodem a uczestnictwo w szkole rodzenia

Table 3. Occurrence of fear of childbirth and the participation in antenatal classes

\begin{tabular}{|c|c|c|c|c|c|}
\hline \multirow{3}{*}{$\begin{array}{c}\text { Uczestnictwo } \\
\text { w szkole } \\
\text { rodzenia/ } \\
\text { Participation in antena- } \\
\text { tal classes }\end{array}$} & \multicolumn{4}{|c|}{$\begin{array}{l}\text { Występowanie lęku przed porodem/ } \\
\text { Occurrence of childbirth }\end{array}$} & \multirow{3}{*}{$\mathrm{p}^{*}$} \\
\hline & \multicolumn{2}{|c|}{ Tak/Yes } & \multicolumn{2}{|c|}{ Nie/No } & \\
\hline & $\mathrm{N} /$ Number & $\%$ & $\mathrm{~N} /$ Number & $\%$ & \\
\hline Tak/Yes & 55 & 83,33 & 11 & 61,11 & \\
\hline $\mathrm{Nie} / \mathrm{No}$ & 11 & 16,67 & 7 & 38,89 & No \\
\hline
\end{tabular}

* test chi-kwadrat/chi-square test

Źródło: opracowanie własne

Source: author's own analysis

Lęk przed porodem najczęściej zgłaszały pierworódki, następnie rodzące drugi raz i wieloródki (Tabela 4). Różnice nie były istotne statystycznie ( $p=0,320)$.

Tabela 4. Występowanie lęku przed porodem a rodność Table 4. Occurrence of fear of childbirth and the parity

\begin{tabular}{|c|c|c|c|c|c|}
\hline \multirow{3}{*}{$\begin{array}{c}\text { Rodnośćl } \\
\text { The numer of births }\end{array}$} & \multicolumn{4}{|c|}{$\begin{array}{l}\text { Występowanie lęku przed porodem/ } \\
\text { Occurrence of fear of childbirth }\end{array}$} & \multirow{3}{*}{$\mathrm{p}^{*}$} \\
\hline & \multicolumn{2}{|c|}{ Tak/Yes } & \multicolumn{2}{|c|}{$\mathrm{Nie} / \mathrm{No}$} & \\
\hline & N/Number & $\%$ & $\mathrm{~N} /$ Number & $\%$ & \\
\hline Pierworódka/Primipara & 58 & 87,88 & 14 & 77,78 & \\
\hline $\begin{array}{l}\text { Rodząca drugi raz/ } \\
\text { Giving birth second time }\end{array}$ & 7 & 10,61 & 3 & 16,67 & NS \\
\hline Wieloródka/Multipara & 1 & 1,51 & 1 & 5,56 & \\
\hline
\end{tabular}

* test chi-kwadrat/chi-square test

Źródło: opracowanie własne

Source: author's own analysis

Wszystkie ankietowane z wykształceniem podstawowym zgłaszały lęk przedporodowy, ze średnim $80 \%$, a z wyższym 75,5\%. Lęku przedporodowego nie zgłaszało $20 \%$ ankietowanych $z$ wykształceniem średnim i $24,5 \%$ z wyższym. Różnice nie były istotne statystycznie $(p=0,320)$.

Lęk przed porodem występował u 91,7\% kobiet w grupie poniżej 20 roku życia, u 82,3\% dwudziestokilkulatek, u 70,8\% ciężarnych w przedziale wiekowym 31-40 r. ż. i u 33,3\% powyżej 40 roku życia. Różnice były istotne statystycznie $(p=0,036)$ (Tabela 5$)$.

Tabela 5. Występowanie lęku przed porodem w zależności od wieku Table 5. Occurrence of fear of childbirth according to age

\begin{tabular}{|c|c|c|c|c|c|}
\hline \multirow{3}{*}{ Wiek/Age } & \multicolumn{4}{|c|}{$\begin{array}{l}\text { Występowanie lęku przed porodem/ } \\
\text { Occurrence of fear of childbirth }\end{array}$} & \multirow{3}{*}{$\mathrm{p}^{*}$} \\
\hline & \multicolumn{2}{|c|}{ Tak/Yes } & \multicolumn{2}{|c|}{$\mathrm{Nie} / \mathrm{No}$} & \\
\hline & N/Number & $\%$ & N/Number & $\%$ & \\
\hline$<20$ r. ż. & 11 & 91,7 & 1 & 8,3 & \multirow{4}{*}{0,036} \\
\hline 21-30 r. ż. & 37 & 82,3 & 8 & 17,7 & \\
\hline 31-40 r. ż. & 17 & 70,8 & 7 & 29,2 & \\
\hline$>40$ r. ż. & 1 & 33,3 & 2 & 66,7 & \\
\hline
\end{tabular}

* test U Manna Whitneya

Źródło: opracowanie własne

Source: author's own analysis
Lęk przed porodem zgłaszały najczęściej ciężar-

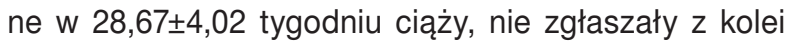
te w 28,78 55,62 tygodniu ciąży (Tabela 6). Różnice nie były istotne statystycznie $(p=0,785)$.

Tabela 6. Występowanie lęku przed porodem a tydzień ciąży Table 6. Occurrence of fear of childbirth and weeks of gestation

\begin{tabular}{ccccc}
\hline & $\begin{array}{c}\text { Występowanie lęku } \\
\text { przed porodem/ } \\
\text { Occurrence of fear of } \\
\text { childbirth }\end{array}$ & $\begin{array}{c}\text { Średnia/ } \\
\text { Average }\end{array}$ & SD & $\mathrm{p}^{*}$ \\
\hline $\begin{array}{c}\text { Czas trwania ciąży } \\
\text { [w tygodniach]/ }\end{array}$ & Tak/Yes & 28,67 & 4,02 & \\
$\begin{array}{c}\text { The duration of pregnancy } \\
\text { [in weeks] }\end{array}$ & Nie/No & 28,78 & 5,62 & NS \\
\hline
\end{tabular}

* test U Manna Whitneya/Mann-Whitney U test

Źródło: opracowanie własne

Source: author's own analysis

Wśród ciężarnych uprawiających sport w trakcie ciąży $73,4 \%$ badanych zgłaszało lęk przed porodem, 26,65 nie zgłaszało (Tabela 7). W grupie nieaktywnych fizycznie 95\% zgłaszało lęk przedporodowy. Różnice nie były istotne statystycznie $(p=0,082)$.

Tabela 7. Występowanie lęku przed porodem a uprawianie aktywności fizycznej w trakcie ciąży

Table 7. Fear of childbirth and physical activity during pregnancy

\begin{tabular}{|c|c|c|c|c|c|}
\hline \multirow{3}{*}{$\begin{array}{l}\text { Uprawianie aktywności } \\
\text { fizycznej w trakcie ciążyl } \\
\text { The level of physical } \\
\text { activity during pregnancy }\end{array}$} & \multicolumn{4}{|c|}{$\begin{array}{l}\text { Występowanie lęku przed porodem/ } \\
\text { Occurrence of fear of childbirth }\end{array}$} & \multirow{3}{*}{$\mathrm{p}^{*}$} \\
\hline & \multicolumn{2}{|c|}{ Tak/Yes } & \multicolumn{2}{|c|}{$\mathrm{Nie} / \mathrm{No}$} & \\
\hline & $\mathrm{N} /$ Number & $\%$ & $\mathrm{~N} /$ Number & $\%$ & \\
\hline Tak/Yes & 47 & 73,4 & 17 & 26,6 & \multirow{2}{*}{ NS } \\
\hline $\mathrm{Nie} / \mathrm{No}$ & 19 & 95,0 & 1 & 5,0 & \\
\hline
\end{tabular}

* test chi-kwadrat/chi-square test

Źródło: opracowanie własne

Source: author's own analysis

\section{Dyskusja}

Większość kobiet i mężczyzn za nadrzędny cel swego życia stawia posiadanie potomstwa. Przyjmują oni wówczas na siebie nowe role społeczne - matki i ojca. Okres oczekiwania na potomka staje się czasem szczytowej motywacji do poszerzania wiedzy na temat opieki i zdrowia nie tylko mającego się urodzić dziecka, ale i samej ciąży [2]. Jedną z inicjatyw podejmowanych przez przyszłych rodziców jest udział w zajęciach szkole rodzenia.

Pizak zaobserwował, że w skutek podniesienia stanu wiedzy u 83,3\% ankietowanych poprawił się stan samopoczucia. Kobiety zapytane o wpływ i przyswajanie wiedzy podczas zajęć stwierdziły zmniejszenie się poziomu lęku przed porodem w $78,57 \%$, a w $89,29 \%$ uważały, że wiedza zdobywana na zajęciach w szkole rodzenia ma wpływ na przebieg ciąży i na przygotowanie psychofizyczne do porodu [3]. 
Bączyk i wsp. zauważyli, iż 1 na 5 kobiet zgłasza lęk przed porodem [3]. Odmienną częstość występowania lęku przedporodowego zauważają Stangret i wsp. W ich badaniach $73,33 \%$ kobiet odczuwało strach przed porodem i tym argumentuje także popularność szkół rodzenia [4]. Horney zauważył, że wraz ze upływem kolejnych dekad zwiększa się liczba kobiet, które odczuwają lęk przez aktem porodu. Również Piela i wsp. przeprowadzając badania wykazali znacznie podwyższony poziom lęku, zwłaszcza u kobiet w wieku 18-35 lat [5]. W naszych badaniach lęk przed porodem najczęściej występował w grupie najmłodszych ciężarnych. Co równie ciekawe, występowanie lęku przedporodowego nie wiązało się z liczbą przebytych ciąż. W naszych badaniach lęk przed porodem zgłosiło $78,57 \%$ ankietowanych.

Olejniczak i Krakowiak zaobserwowali, że szkoła rodzenia powinna spełniać następujące role: przygotowanie psychofizyczne do porodu $(51,4 \%)$, zmniejszenie lęku przed porodem (38,3\%), pozytywna zmiana postawy męża $(15,9 \%)$ [6]. W naszych badaniach za najważniejsze zadania szkoły rodzenia ciężarne uznały zmniejszenie lęku przed porodem - $65,48 \%$, odpowiednie przygotowanie sprawnościowe do porodu $-65,48 \%$ i poznanie fizjologii ciąży $-57,14 \%$.

\section{Wnioski}

Aktywne uczestnictwo w zajęciach szkoły rodzenia pozytywnie przekłada się na zmniejszenie lęku i stresu przedporodowego. Lęk przedporodowy zależny jest od wieku ciężarnej w większym stopniu niż od rodności.

\section{Piśmiennictwo}

1. Kwiatek M, Gęca T, Biegaj-Fic J. Szkoła rodzenia - Profil pacjentek oraz wpływ zajęć na przebieg porodu oraz stan noworodka. Med Ogólna. 2011; 17: 111-115.

2. Wdowiak A, Kędzierska A, Sadowska M. Efektywność funkcjonowania szkół rodzenia w opinii kobiet. Eur J Med Tech. 2013; 1: 39-47.

3. Bączyk G, Cebulska V, Koźlak V, Michalak M, Bajek A. Poziom lęku przedporodowego u kobiet w ciąży. Probl hig. 2011; 92: 774-777.

4. Stangret A, Cendrowska A, Szukiewicz D. Wpływ Szkoły Rodzenia na subiektywną ocenę przygotowania teoretycznego i sprawnościowego do porodu. Nowa Med. 2008; 2: 2-6.

5. Piela B, Skrzypulec V, Sobik N. Ocena objawów depresji i lęku u kobiet w ciąży podwyższonego ryzyka. Ann Acad Med Siles. 2005; 59: 292-297.

6. Olejniczak D, Krakowiak K. Ocena potrzeby edukacji zdrowotnej kobiet w ciąży w zakresie stylu życia i karmienia piersią. Nowa Pediatr. 2013; 3: 97-105.

Artykuł przyjęty do redakcji: 10.08.2016

Artykuł przyjęty do publikacji: 13.09.2016

Źródło finansowania: Praca nie jest finansowana z żadnego źródła. Konflikt interesów: Autorzy deklarują brak konfliktu interesów.

\section{Adres do korespondencji:}

Sławomir Szymański

ul. Żołnierska 48,

71-210 Szczecin

tel.: 604970670

e-mail: sszymanski@o2.pl

Zakład Pielęgniarstwa Położniczo-Ginekologicznego,

Pomorski Uniwersytet Medyczny w Szczecinie 